\title{
REVIEWERS' COMMENTS
}

Kushkevych I. V. Intestinal Sulfate-Reducing Bacteria. Masaryk University, Brno, Czech Republic, 2017. - 320 p.

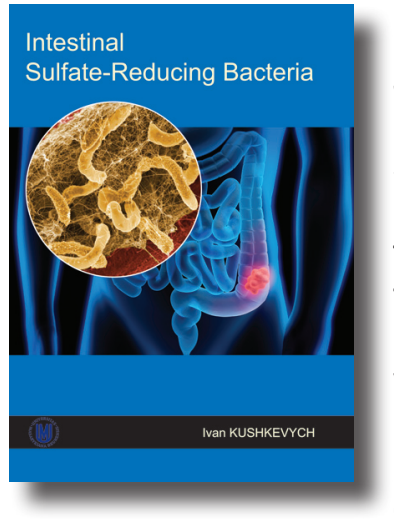

Since my early investigations with Harry D. Peck, Jr and Jean LeGall, I have been interested in the anaerobic sulfatereducing bacteria. While my research initially addressed stress response in sulfate reducers, our research group in the past few years has expanded into studying the effect of sulfate-reducing bacteria on irritable bowel disease. It was through this interest in intestinal sulfate-reducing bacteria that I first became aware of the publications of Dr. Ivan Kushkevych. Thus, I have read this monograph with more than casual interest and have concluded that it is an extraordinary contribution which merits publication. In the following, I'll provide comments to support my evaluation.

The initial chapter provides background information on the salient characteristics of the sulfate-reducing bacteria including their activities in the intestine. Since this monograph is intended, in part, to be used by students new to the subject, the illustrations and laboratory techniques enable the reader to achieve a deep understanding of the subject. The community structure involving the sulfate reducers is discussed and the role of these bacteria in the gut of healthy individuals is presented. Additionally, the potential role of sulfate-reducing bacteria contributing to intestinal inflammation is reviewed. While some scientists consider that the growth of sulfate-reducing bacteria is attributed to sulfur supplied only in the diet, Dr. Kushkevych appropriately includes in his discussion the contribution of sulfated mucins as a sulfate source in the intestine. The subject of inflammatory bowel diseases is an excellent research topic for students because it includes basic science, bacterial ecology and cell biology. The current understanding of intestinal inflammation attributed to hydrogen sulfide is skillfully presented. The second half of the first chapter describes his successful attempts to isolate sulfate reducers from healthy individuals and those with colitis. This study using molecular biology and classical microbiology provides an extensive comparison of biochemical and physiological characteristics of these bacteria from different hosts.

The technical aspects of strain identity and molecular comparisons were nicely handled and the information provided is useful.

() 2018 L. Barton et al.; Published by the Ivan Franko National University of Lviv on behalf of Біологічні Студії / Studia Biologica. This is an Open Access article distributed under the terms of the Creative Commons Attribution License (http://www.budapestopenaccessinitiative.org/ and Creative Commons Attribution 4.0 License), which permits unrestricted reuse, distribution, and reproduction in any medium, provided the original work is properly cited.

ISSN 1996-4536 (print) • ISSN 2311-0783 (on-line) • Біологічні Студії / Studia Biologica • 2018 • Том 12/№1 • С. 141-148 
From a series of sulfate reducers that he had isolated from humans, two strains of bacteria (Desulfovibrio piger Vib-7 and Desulfomicrobium orale Rod-9) were extensively characterized and the second chapter carries this information. The enzymology employed provides an excellent overview of metabolism related to the specific energetics typical of sulfate-reducing bacteria. An interesting and significant revelation from his study of sulfite reductase is the production of thiosulfate, trithionate, and tetrathionate as end products. While these end products of sulfite reductase had been reported in the early 1970s from the laboratories of Peck and others, it became generally accepted that the physiologically relevant end product of sulfite reductase by pure cultures was only hydrogen sulfide. However, it may be important to reopen this end product issue of sulfite reductase because in mixed cultures with sulfate-reducing bacteria, such as the intestine, the concentration of sulfate and sulfite would not be expected to be static but to vary considerably.

The third chapter is an extensive evaluation of all relevant parameters impacting hydrogen sulfide production by $D$. piger Vib-7. It may be relevant to compare the optimal conditions for hydrogen sulfide by D.piger Vib-7 to other sulfate reducers; however, that information is not available in the open literature. The capability of $D$. piger Vib-7 and Desulfomicrobium orale Rod-9 to resist oxygen stress by catalase and superoxide reductase is an important characteristic and usually not addressed by others examining the activity of sulfate-reducing bacteria in the colon. However, it is relevant since oxygen diffuses inward from the intestine periphery. Even though the lumen of the intestine is anaerobic, microaerophilic conditions exist near the colonic cells (see report by Levitt et al., J Clin Invest. 1999; 104: 1107) and persistence of anaerobic bacteria in the gut would benefit from an active oxygen detoxification process.

In the final chapter, the description of colon disease attributed to hydrogen sulfide is provided. Information concerning development of an inflamed bowel in rats by sulfate reducers is a useful resource for other scientist addressing a similar topic. The literature referenced here is up to date and models describing activity of host cells with bacterial end products are appropriately detailed. Since one of the directions for future studies focuses on probiotics and antibiotics, the research and discussion provided here is timely. The creation of a mutant strain of $D$. piger Vib-7 and the use of this strain as a probiotic treatment for intestinal disease is indeed interesting. It is highly imaginative and displays that Dr. Kushkevych is "thinking outside the box" as far as research is concerned.

When considering the entire monograph, the reader will appreciate that he has clearly discussed a complex research in a logical and fact-driven manner. Obviously, Dr. Kushkevych has a deep understanding of the topic and writes in a style that makes the monograph comfortable to read. The topic is timely and important since the etiology of irritable bowel syndrome is yet to be established. The evolution of the research in the chapters indicates that he has the organizational skill and the research dedication that is found in mature scientists and important for directing research projects. This scientific contribution of Dr. Kushkevych is comparable to that of an individual from a well-established laboratory where one would have benefited from a lengthy research history addressing the topic of the intestine and sulfate-reducing bacteria. Thus, Dr. Kushkevych has achieved a lot over a short amount of time. Over the years, I have edited books on the topic of "The Sulfate-Reducing Bacteria" and a contribution of Dr. Kushkevych such as presented in this monograph would be an appropriate chapter in a future book.

ISSN 1996-4536 (print) • ISSN 2311-0783 (on-line) • Біологічні Студії / Studia Biologica • 2018 • Том 12/№1 • С. 141-148 
Thus, I enthusiastically support the publication of this monograph because it will be useful to physicians, scientists and students. The work is original, of high quality and his generation of a bacterial strain appropriate for probiotic use is intriguing.

Sincerely,

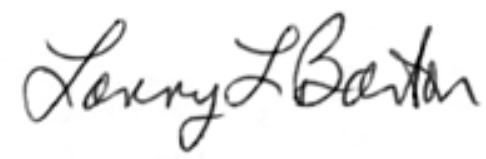

Professor Larry L. Barton, Ph.D.,

Professor at the Department of Biology

at the University of New Mexico (United States of America)

\section{***}

Intestinal sulfate-reducing bacteria are studied in just a few laboratories in the world, including our laboratory at the Department of Food and Nutritional Sciences at University of Reading. Most of our research is focused on intestinal microflora and food microbiology.

This monograph is dedicated to the science of gut sulfate-reducing bacteria. As a researcher involved in studying these bacteria, I can say that they are fascinating, frustrating, compelling and noxious. They are known to uptake hydrogen in the lower gut but also have a possible role in disease aetiology - not least of which is their possible role in the toxicology of the Inflammatory Bowel Disease (IBD), Ulcerative Colitis. The ultimate role of sulfate-reducing bacteria in IBD of humans and animals is still not well studied. To solve such complex problems is very important to isolate new strains of these bacteria from the intestines of people and animals, both healthy persons and persons with inflammatory bowel disease, and study the process of dissimilatory sulfate reduction and pathology.

Special attention in this book is paid to the isolation and identification of sulfatereducing bacteria from the intestinal tract. The author describes their morphological, physiological and biochemical properties in detail. Growth of isolates and their process of dissimilatory sulfate reduction are also described. Based on the parameters of bacterial growth and dissimilatory sulfate reduction, cluster, cross-correlation and dispersion analysis is demonstrated. By sequences analysis of 16S rRNA gene of intestinal sulfate-reducing bacteria are identified.

Studies on biochemical properties of intestinal sulfate-reducing bacteria are described, in particular enzymes involved in the process of sulfate dissimilation (ATP sulfurylase, pyrophosphatase, APS reductase, sulfite reductase, lactate dehydrogenase, pyruvate:ferredoxin-oxidoreductase, hydrogenase, phosphotransacetylase, acetate kinase). The author, for the first time, has explored the activity of these enzymes in detail and studied the kinetic properties of their reactions. This will lead towards better understanding of the mechanisms of sulfate reduction in humans or animal intestines.

This monograph also describes the physiological characteristics of bacteria Desulfovibrio piger Vib-7, including the process of process of dissimilatory sulfate reduction under the influence of different $\mathrm{pH}$, concentration of hydrogen sulfide, electron acceptor and donors. The author has built $3 D$ surfaces demonstrating optimal maximum of dissimilatory sulfate reduction. Based on the studied parameters of dissimilatory sulfate reduction process, a mathematical model has been created.

ISSN 1996-4536 (print) • ISSN 2311-0783 (on-line) • Біологічні Студії / Studia Biologica • 2018 • Том 12/№1 • С. 141-148 
One experimental approach is development of a method of creating animal models of Ulcerative Colitis involving intestinal sulfate-reducing bacteria. This method is promising as it provides an opportunity to study the aetiological role of these bacteria in diseases of the colon, assess their aggressiveness based on the production of hydrogen sulfide and ulceration. Special aetiological and functional roles of sulfate-reducing bacteria in bowel disease development are of great scientific interest. Further improvement of animal models of colitis using sulfate-reducing bacteria and detection of their metabolism products (e.g. hydrogen sulfide) may opens up new opportunities for early diagnosis of Inflammatory Bowel Disease and possibly some carcinogenesis. This is extremely relevant to modern biology, veterinary science and medicine. The monograph of Ivan Kushkevych's, looks at the above the mentioned problems.

One special interested of the author is in molecular and genetic construction of sulfate-reducing bacteria which are able to synthesize cysteine from hydrogen sulfide. The molecular cloning cysK gene from E. coli and its genetic transferring in the intestinal sulfate-reducing bacteria Desulfovibrio piger Vib-7 was carried out as well as the expression analysis of the enzyme studied. Cysteine synthesis from hydrogen sulfide, as a substrate in the $D$. piger Vib-7 strain for the first time, was demonstrated and characterised. The expression of the cysK gene in the mutant-type was studied by the formation of the final reaction product (cysteine) and the activity of $O$-acetylserine(thiol) lyase enzyme. The obtained genetically constructed mutant strain of $D$. piger Vib-7 for therapeutic strategies may be applied in the future.

Scientific and theoretical results as well as conclusions presented in the book are important for characterising the biochemical and physiological parameters of intestinal sulfate-reducing bacteria under different conditions.

It should be noted that the Ivan V. Kushkevych's monograph is of fundamental microbiological interest, in that it describes the current state of research problems of aetiological and functional role of sulfate-reducing bacteria in the development of large intestine diseases of humans and animals. These results may be important for medicine and veterinary science in understanding the causes and development of human and animal intestinal pathologies and to regulate the number of these bacteria, and, accordingly, the accumulation of toxic hydrogen sulfide.

There is reason to expect that the monograph will be useful to food microbiologists, gastroenterologists, and other scientists interested in intestinal sulfate-reducers and inflammatory bowel disease. I have reviewed this monograph and am positive about its contents and therefore recommend it to be published.
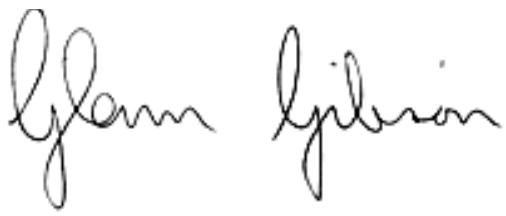

Professor Glenn Gibson, Ph.D.,

Professor of Food Microbiology,

Head of Department of Food and Nutritional Sciences

at the University of Reading (United Kingdom)

ISSN 1996-4536 (print) • ISSN 2311-0783 (on-line) • Біологічні Студії / Studia Biologica • 2018 • Том 12/№1 • C. 141-148 
The role of sulphate-reducing bacteria (SRB) in the human intestine is an important but much neglected area of study. The central role of SRB in hydrogen metabolism in the gut, and in addition in soil and marine sediments, is critical in maintaining normal function, whilst at the same time the end-products of dissimilatory sulphate reduction such as hydrogen sulphide are highly toxic. I am therefore pleased that Dr. Kushkevych has chosen this area of study for his monograph.

The monograph opens with a comprehensive review of sulphate reducing bacteria, their various habitats, their characteristics both metabolic, microbiological, and genetic and their metabolism. This review is comprehensive and informative, up to date, well written and illustrated. It provides an excellent overview of SRB and will be of value to anyone wanting to learn about these bacteria and their role in nature. The wide range of substrates used by SRB is important to recognise, as is the variable carriage rate of these species across different populations of the world. The observation that oral sulphate supplements suppress methanogenesis in humans was I think first described by Christl in 1992. The section on hydrogen metabolism in the gut is a good summary of what is known on this subject. I note that much of the literature on the subject dates from around 20 years ago. It is a pity that this important area of gut physiology, with such implications for health, has not received more attention. This makes the monograph all the more important and Dr. Kushkevych is to be congratulated for pursuing his studies in this area over many years.

The co-existence of SRB with other microorganisms in various environments is well described. I was most interested to note the role of SRB at the junction between aerobic and anaerobic layers in marine sediments, where sulphate is in abundance. The importance of SRB as electron acceptor and the role of oxygen in detoxifying the products of metabolism in this unique ecosystem is an important point to make. This discussion leads naturally to a consideration of what is happening at the mucosal surface in the large intestine. Whilst the microflora of the mucosal surface are largely the same as those in the lumen the potential for more oxygen to be present is important. Dr. Kushkevych gives a useful overview of fermentation reactions in these consortia and the likely interactions with the gut epithelium. This is clearly important in considering the aetiology of inflammatory bowel diseases. In this context it is worth remembering that sulphur amino acids are a significant source of sulphide in the large bowel (Magee American Journal of Clinical Nutrition, 2000 72: 1488-1494) and that meat has been linked to the cause of large bowel cancer. However experimental evidence for this link is difficult to obtain whilst that relating to ulcerative colitis in more readily available. Dr. Kushkevych makes a good case for SRB/sulphide being involved in the inflammatory process with evidence from animal studies and human observational epidemiology. Why colitis should always start in the rectum is something that I have always found puzzling.

I am pleased to see that Dr. Kushkevych has done some studies of the human gut flora in both healthy and colitis patients. The characteristic pattern of bacteria in colitis, high SRB and low 'protective' bacteria such as Bifidobacteria and Lactobacilli is important to note and should be of interest to the manufacturers of probiotic products. The higher concentrations of sulphide in colitis faeces would support these findings but

ISSN 1996-4536 (print) • ISSN 2311-0783 (on-line) • Біологічні Студії / Studia Biologica • 2018 • Том 12/№1 • С. 141-148 
should be interpreted only in the knowledge of what diets these people were eating. I am not competent to comment on the 'Isolation and identification of intestinal sulfatereducing bacteria', which requires a detailed knowledge of these techniques for growing $\mathrm{SRB}$ etc. but it is reassuring to note that all the species isolated were members of the Desulfovibrio and Desulfomicrobium genera confirmed by $16 \mathrm{~S}$ rRNA analysis. I am interested to learn about $D$. piger. The use of cluster analysis and various cross-correlation analyses is impressive and reassuring to know that 'the mechanisms of sulfate reduction process in intestinal SRB of different genera are almost identical'. This work uses state-of-the-art techniques to give us valuable information about SRB in the gut and their potential to cause disease.

The chapter on dissimilatory sulphate reduction is detailed, comprehensive and contains more information than most textbooks on the subject. I am particularly please that Dr. Kushkevych has given equal weight to the presence of inorganic sulphate and sulphite in the human diet. Sulphite is widely used by the food industry as a preservative especially in beer, wine, processed and preserved/dried food. This source is available for reduction in the anaerobic environment of the hindgut where the production of hydrogen sulphide is a potentially toxic by-product. This is an issue that the food industry has not yet fully addressed, but should do so. The two strains chosen for study D. piger Vib-7 and D. orale Rod-9 are not familiar to me but I note they have been isolated from the human gut. The differences in sodium and potassium transport and ATPase activity between these two strains in interesting but in the physiological environment of the gut may not be limiting. The temperature optima are close to physiological.

The kinetic parameters of dissimilatory ATP sulfurylase activity and differences are shown between the two chosen bacteria. The role of substrate concentration in determining the kinetic parameters of the enzyme is not surprising but the $\mathrm{pH}$ optimum of between 8 and 9 is less easy to understand since this $\mathrm{pH}$ will not be encountered in the large bowel as Dr. Kushkevych acknowledges on page 127 of the monograph. So, at pH 6-7 activity is only $50 \%$ of maximum. Similarly with APS reductase. The increase in sulphite reductase activity with increasing concentrations of sulphide is well within parameters found in the gut and levels that might be considered toxic to epithelial cells. The high production rate by some of these Desulfovibrio species leads to concern about their presence and activity in the human gut. The electron donors are well described. Overall this chapter is outstanding for the detailed kinetic studies that have been performed, its comprehensive analysis of all the stages of dissimilatory sulphate reduction and especially for the very high quality of the illustrations throughout the text.

Dr. Kushkevych the goes on to describe the basic physiology of $D$. piger strain Vib-7. The effect of change in $\mathrm{pH}$, concentration of accumulated hydrogen sulfide, concentration of electron acceptor/donor and the total number of SRB in the gut on the growth and metabolism of $D$. piger are important fundamental information about this strain. Based on experimental data, $3 D$ surfaces models have been built for the first time showing optimal maximum points of dissimilatory sulfate reduction under these conditions. A mathematical model of this process is created and basic kinetic parameters calculated, including the critical points of the process, absolute, specific and maximum rates of $D$. piger Vib-7 growth, their consumption of sulfate and lactate with production of hydrogen sulfide and acetate. The potential for hydrogen sulphide from amino acid fermentation to inhibit the metabolism of SRB is important. The production

ISSN 1996-4536 (print) • ISSN 2311-0783 (on-line) • Біологічні Студії / Studia Biologica • 2018 • Том 12/№1 • С. 141-148 
of catalase and superoxide dismutase by $D$. piger may have more general applicability to the growth of strict anaerobes in low oxygen environments. This chapter contains a lot of valuable and original data, which will provide a reference source for those interested in SRB worldwide.

Of particular interest to me as a gastroenterologist is the development of animal models of ulcerative colitis to help explore the role of SRB and their metabolites, principally hydrogen sulphide, in causing inflammation in the colonic mucosa. The cellular toxicity of hydrogen sulphide is well reviewed here, its ready diffusion into epithelial cells and importantly the protective role of butyrate, first described by Roediger. Clearly diet will have a major role to play in providing substrates e.g.various carbohydrates, through fermentation for the production of protective factors along with the substrates e.g. s-amino acids, inorganic sulphate and sulphite and small amounts of $\mathrm{SO}_{4}$ present as active groups in some polymers, required for sulphide production. The DNA damaging role of sulphide has received much less important and I am pleased to see it mentioned here. The intracellular detoxification of suphide by Rhodanase and Thiol S-methyltransferase is critical to our understanding of the fate of sulphide intracellularly. The changes in the rat gut microflora by the three diets are intriguing. Fig 4.8 contains a lot of useful data. The addition of Postgate's medium clearly supplied extra substrate for what are presumably autochthonous SRB but the added SRB given orally would not be expected to have such a large effect given that gastric and small bowel defences would diminish their viability. However the significant increase in sulphide concentrations in Group III signifies a role for oral bacteria. The reduction in the numbers of "protective" species is important to note. The progressive rise in sulphide concentrations along the large bowel would go alone with declining carbohydrate availability after the caecum. The progressive appearance of ulceration of the mucosa shows that this is a good model. Some histological evidence for the pathology would be useful to obtain.

The cysK gene mutant of $D$. piger Vib-7 as genetically constructed is fascinating and certainly offers the potential for therapeutic intervention in colitis. However, at the present time, there is a lot of antipathy amongst the public, and legislators in the EC, to the use of genetically modified organisms - which is a pity. The value of antibiotics in treating colitis has been disappointing although I would like to see more combinations being used especially with the sulphasalazine-type drugs. The problem of reaching the mucosal surface is perhaps not so critical as the development of resistance. Overall these are intriguing studies that offer potential for therapeutic developments in the future.

In his conclusions Dr. Kushkevych is correct in arguing that we should pay attention to the gut microflora when trying to understand the pathogenesis of ulcerative colitis. In animal models no bacteria equals no inflammation. Using SRB and its products as biomarkers of risk and treatment is worth pursuing although many laboratories will not have the facilities to do this and inflammatory markers are better established. And certainly trying to identify suitable antimicrobials should be possible. The point that Dr. Kushkevych makes about 'the number of Lactobacillus and Bifidobacterium is reduced by 6-7 orders' is also very important and may open up other avenues to management and prevention. $D$. piger may have a role in this context.

In conclusion I am impressed by the high quality, originality and range of studies that Dr. Kushkevych reports together with his understanding of the importance of

ISSN 1996-4536 (print) • ISSN 2311-0783 (on-line) • Біологічні Студії / Studia Biologica • 2018 • Том 12/№1 • С. 141-148 
sulphate-reducing bacteria in nature and especially in the hindgut. I agree that these results will be of interest to medical and veterinary science as well as the community of nutritionists. The monograph is very well presented and is an important contribution to the subject. I strongly recommend that it be published and in addition I hope that Dr. Kushkevych will report more of his studies in the scientific literature.

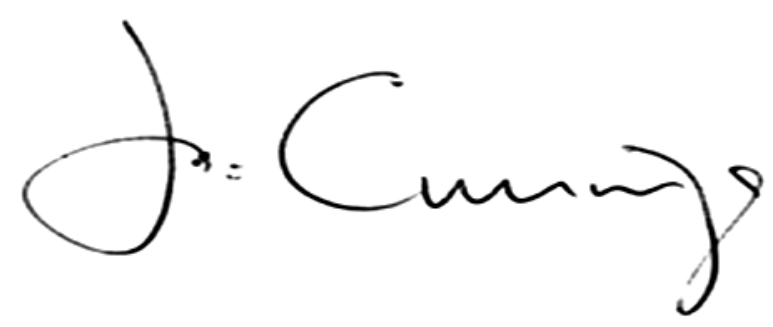

Professor John H. Cummings, Ph.D.,

Professor of Experimental Gastroenterology,

Division of Cancer Research, Medical Research Institute,

School of Medicine at the University of Dundee (Scotland, United Kingdom) 